\title{
Does the Length of Fielding Period Matter? Examining Response Scores of Early Versus Late Responders
}

\author{
Richard Sigman ${ }^{1}$, Taylor Lewis ${ }^{2}$, Naomi Dyer Yount ${ }^{1}$, and Kimya Lee ${ }^{2}$
}

This article discusses the potential effects of a shortened fielding period on an employee survey's item and index scores and respondent demographics. Using data from the U.S. Office of Personnel Management's 2011 Federal Employee Viewpoint Survey, we investigate whether early responding employees differ from later responding employees. Specifically, we examine differences in item and index scores related to employee engagement and global satisfaction. Our findings show that early responders tend to be less positive, even after adjusting their weights for nonresponse. Agencies vary in their prevalence of late responders, and score differences become magnified as this proportion increases. We also examine the extent to which early versus late responders differ on demographic characteristics such as grade level, supervisory status, gender, tenure with agency, and intention to leave, noting that nonminorities and females are the two demographic characteristics most associated with responding early.

Key words: FEVS; employee surveys; employee satisfaction; employee engagement; fielding period.

\section{Introduction}

Employee surveys are used by government and private establishments worldwide (Kraut 1996). Many organizations use employee surveys as a cost-effective way to gauge the extent to which employees' beliefs and perceptions are in line with the organization's mission and goals. These surveys can convey employee morale, and they can also provide direct, actionable information about employee satisfaction and engagement, intent to leave, and training needs. A distinct advantage of employee surveys is that they may alert management to budding problems before they become serious and prevent the loss of an organization's most important asset, their employees.

However, along with these advantages, there are also unique challenges associated with employee surveys. Since employee surveys are voluntary, nonresponse and the effect it can have on estimates is always a concern (Rogelberg and Stanton 2007). Indeed, response rates to employee surveys have declined over the past few decades (Baruch and Holtom 2008), as they have for surveys in general (de Leeuw and de Heer 2002). A longer period

${ }^{1}$ Westat, 1600 Research Blvd, Rockville, MD 20850 U.S.A. Email: RichardSigman@westat.com and NaomiYount@westat.com

2 U.S. Office of Personnel Management, 1900 E Street, NW, Washington, DC 20415, U.S.A. Email: Taylor.Lewis@opm.gov and Kimya.Lee@opm.gov

Acknowledgments: The opinions, findings, and conclusions expressed in this article are those of the authors and do not necessarily reflect those of the U.S. Office of Personnel Management. 
of data collection may boost response rates, but comes at the costs of less timely data and higher administrative costs (e.g., following up with nonrespondents, staffing survey support centers). Faced with the unfortunate reality of stagnant or reduced data collection budgets, many survey managers find themselves questioning whether the fielding period could be shortened without adversely affecting the quality of data produced.

A natural way to evaluate a shortened fielding period is to compare the response patterns and demographic profiles for some definition of "early" versus "late" respondents. Studies with this goal in mind have a long and rich history in the survey research literature. Some of the many examples include Baur (1947), Newman (1962), Mayer and Pratt (1966), Gannon et al. (1971), Filion (1975), and Bates and Creighton (2000). In terms of demographics, these studies have found that early respondents tend to be older (Filion 1975), nonminority (Mayer and Pratt 1966), and female (Gannon et al. 1971), and of a higher education level or socioeconomic status (Newman 1962; Mayer and Pratt 1966).

With respect to attitudinal measures captured as part of a self-administered employee survey, the literature is much less robust, but a few examples are Pace (1939), Schwirian and Blaine (1966), Ellis et al. (1970), Green (1991), and Borg and Tuten (2003). Arguably the most pervading theme is that few noteworthy differences are found. For instance, Pace (1939), Green (1991), and Borg and Tuten (2003) essentially concluded there were no significant differences for questions asking about various dimensions of job satisfaction, whereas Schwirian and Blaine (1966) found early respondents tended to be more satisfied, although differences were slight.

As is generally the case with establishment surveys, a feature of the employee survey response timing studies identified above is that the target populations are often highly specialized. For example, Pace (1939) studied recent college graduates, Schwirian and Blaine (1966) studied members of the United Automobile Workers union, Green (1991) studied teachers, and Borg and Tuten (2003) studied employees of two German advanced technology companies. It is unclear whether these findings generalize to other employee populations. To the best of our knowledge, there has never been any research aimed specifically at our target population of interest, employees of the United States federal government. This article offers one such contribution, as we examine data from the U.S. Office of Personnel Management's (OPM) 2011 Federal Employee Viewpoint Survey (FEVS).

Section 2 provides some background about the FEVS. The remainder of the article utilizes 2011 FEVS data to determine the effects of reducing the length of the FEVS data collection period to two weeks. Section 3 provides a comparison of the demographic characteristics of early responders versus late responders. Section 4 compares earlyresponder estimates with all-responder estimates. Section 5 contains our conclusions.

\section{Background About the FEVS}

OPM conducts the FEVS to collect data on U.S. federal government employees' opinions of whether, and to what extent, conditions that characterize successful organizations are present in their agency, focusing on critical drivers of employee satisfaction, engagement, commitment, and retention. Results from the survey enable OPM and agency managers to take positive steps that have a direct effect on the workplace, such as developing policies 
and action plans that improve agency performance. The 95-item questionnaire consists of eight topic areas: personal work experiences, work unit, agency, supervisor/team leader, leadership, satisfaction, work/life, and demographics. Demographic items include location of employment (headquarters vs. field), supervisory status, gender, ethnicity/race, age, grade, federal employment tenure, and agency tenure. In addition, the survey includes items capturing intent to leave the organization and plans to retire. OPM administered the FEVS for the first time in 2002 and repeated biennially through 2010, when it began to be administered annually.

The sample frame is constructed from a personnel database maintained by OPM that contains information on over 2,000,000 federal civilian employees. For the 2011 FEVS, the total sample size was 560,084, consisting of full-time, permanent employees from 83 agencies on board as of September 2010. A total of 1,114 strata were formed by the cross-classification of (1) organizational subgroup (e.g., bureaus or offices within a larger agency) and (2) supervisory status (nonsupervisors, supervisors, and executives). Note that some degree of stratum collapsing was performed (e.g., if the executive stratum within a given organizational subgroup contained only a few individuals, it was collapsed with the supervisor stratum) and not all three supervisory strata are present within all organizational subgroups. Stratum sample sizes were initially calculated to achieve a $+/-5 \%$ margin of error within each, accounting for nonresponse, though some agencies requested a full census of their workforce.

The FEVS is primarily a web-based, self-administered survey, but a limited number of people (less than 5,000) without Internet access are provided with a paper version of the instrument. Electronically surveyed individuals are sent an initial email invitation to participate that contains a hyperlink to the survey site with a unique respondent key embedded. Time stamps for each response are recorded, and weekly reminder emails are sent only to those who have not completed their survey. The response rate for FEVS 2011 was $48 \%$, calculated according to the RR3 formula defined by the American Association for Public Opinion Research (AAPOR 2009).

To mitigate the potential biases attributable to unequal probabilities of selection across strata and uneven patterns of nonresponse, a three-stage procedure is implemented to develop and append a weight to each respondent's survey record (Kalton and Flores-Cervantes 2003). First, a base weight equaling the reciprocal of the probability of selection is calculated for all sampled employees. Second, weighting cells are formed independently for each agency, within which base weights of nonrespondents are shifted to respondents. The sample frame variables used to form these weighting cells include supervisory status, sex, minority status, age group, length of service as a federal employee, and workplace location (headquarters vs. field office). The free, SAS-callable \%search macro developed by researchers at the University of Michigan (http://www.isr.umich.edu/ $\mathrm{src} / \mathrm{smp} / \mathrm{search} /$ ) is employed to partition each agency's sample into cells, with the goal of differentiating the response probabilities as much as possible across cells. The \%search macro is based on techniques discussed in Sonquist et al. (1974). Third, respondent weights are raked such that the raked weights aggregate to frame totals for the sampling strata and for raking cells defined by agency, gender, and minority status.

Aside from demographics, most survey items are attitudinal, using five-point response scales ranging from "Strongly Agree" to "Strongly Disagree," sometimes with a "Do Not 
Know" or "No Basis to Judge" option provided. A common calculation for summarizing FEVS responses is to compute an item's percent positive estimate. This is found by dichotomizing the response scale into positive responses and nonpositive responses (e.g., a positive response would consist of those answering "Strongly Agree" or "Agree"). Nonsubstantive answers such as "Do Not Know" are treated as missing. The percent positive estimate is simply the weighted portion of positive responses relative to all substantive responses. Jacoby and Matell (1971) have found that converting multi-level Likert-item data to dichotomous or trichotomous measures does not result in any significant decrement in reliability or validity.

Percent positive estimates for certain thematically-linked survey items are averaged to form indices. There are six such indices reported at the governmentwide and agency levels: four Human Capital Assessment and Accountability Framework (HCAAF) Indices, an Employee Engagement Index, and a Global Satisfaction Index. This article focuses on the last two, which were of particular interest because they were first developed and reported following the 2011 administration of the FEVS (OPM 2011). The 15-item Employee Engagement Index is comprised of three subindices: Leaders Lead, Supervisors, and Intrinsic Work Experience. Each of the subindices is composed of five items. Employee engagement can be defined in numerous ways (Macey and Schneider 2008). For the purposes of this study, employee engagement is defined as “. . . passion and commitment the willingness to invest oneself and expend one's discretionary effort to help the employer succeed" (Erickson 2005, 14). While the FEVS does not directly measure employee engagement, the 15 items making up the index are items representing work conditions or perceptions that would lead one to be engaged. The Global Satisfaction Index is composed of four items, addressing employees' satisfaction with their job, pay, organization, plus their willingness to recommend their organization as a good place to work.

\section{Comparison of Early and Late Responders}

In the 2011 FEVS, agencies had staggered fielding periods from April to May 2011 ranging from three to nine weeks in the field. For the purposes of this article, we define an early responder as one who completed the survey within the first two weeks after the initial email invitation to participate was sent. We also considered several other definitions of an early responder (e.g., first half of the field period, first month). However, after observing that the agency-specific percentages of early responders using these alternative definitions often constituted nearly 100 percent of the final set of responders, whether early or late, we felt the two-week threshold allowed for more meaningful comparisons. We also felt this offered a degree of standardization, considering how agencies were given some flexibility in setting their survey launch and close dates. In fact, about one in four agencies evaluated in this study had a fielding period lasting one month or less, which partially explains our initial point. Lastly, we note that because their response times were not precisely captured, in this study we excluded data for the small subset of paper survey responders.

Many of the 83 agencies participating in FEVS 2011 were small and did not include demographic items on their survey. In order to only compare estimates with stable standard errors, and to be able to compare demographic profiles, we restricted our analysis to the 30 agencies for which at least 1,000 responses were obtained and demographic questions 
were included. Appendix A lists these agencies with a few other distributional statistics regarding their respective fielding periods (e.g., response rates, length in the field). In this article, estimates and figures labeled as governmentwide refer only to these 30 agencies, making up $98 \%$ of the target population and 253,285 of the total 266,376 electronically completed surveys for all participating agencies, or $95 \%$ of all responses. A completed survey is defined as an individual who answered at least one-quarter of the 84 core nondemographic survey items. As can be gathered from Appendix A, approximately $59 \%$ of the 253,285 respondents in this study completed the survey in the first two weeks, but the figure varies widely by agency: ranging from $43 \%$ early respondents to $86 \%$.

\subsection{Comparing Demographic Profiles of Early and Late Responders}

Table 1 presents a governmentwide comparison of certain unweighted demographic distributions of early and late respondents. The largest difference found in Table 1 is how minorities are much more likely to respond after the first two weeks. While minorities make up $31 \%$ of early respondents, they constitute $39 \%$ of late respondents. Females are more likely to respond early, although the discrepancy is slightly smaller, with a difference of 3.2 percentage points. Responders 60 years of age or older are also more likely to

Table 1. Governmentwide demographic distributions for early and late responders

\begin{tabular}{|c|c|c|c|c|c|}
\hline Demographic & Value & All & Early & Late & $\begin{array}{c}\text { Difference } \\
\text { between } \\
\text { early and } \\
\text { late }\end{array}$ \\
\hline \multirow[t]{3}{*}{ Age } & $<40$ & 21.1 & 20.9 & 21.3 & -0.4 \\
\hline & $40-59$ & 65.9 & 65.5 & 66.3 & -0.8 \\
\hline & $60+$ & 13.1 & 13.5 & 12.4 & 1.1 \\
\hline \multirow[t]{3}{*}{ Agency tenure } & $<5$ years & 30.8 & 31.6 & 29.5 & 2.1 \\
\hline & $6-20$ years & 41.1 & 40.7 & 41.7 & -1 \\
\hline & $20+$ years & 28.1 & 27.7 & 28.8 & -1.1 \\
\hline \multirow[t]{3}{*}{ Intent to leave } & Stay & 71.0 & 69.9 & 72.7 & -2.8 \\
\hline & Retire & 6.4 & 6.5 & 6.1 & 0.4 \\
\hline & Leave & 22.6 & 23.5 & 21.2 & 2.3 \\
\hline \multirow[t]{2}{*}{ Minority status } & Nonminority & 65.7 & 69.0 & 61.0 & 8.0 \\
\hline & Minority & 34.3 & 31.0 & 39.0 & -8.0 \\
\hline \multirow[t]{5}{*}{ Pay category } & Federal wage system & 3.5 & 3.3 & 3.7 & -0.4 \\
\hline & GS $1-6$ & 5.0 & 5.4 & 4.5 & 0.9 \\
\hline & GS 7-12 & 39.1 & 40.1 & 37.7 & 2.4 \\
\hline & GS $13-15$ & 44.7 & 43.5 & 46.4 & -2.9 \\
\hline & SES, SL, and other & 7.8 & 7.7 & 7.8 & -0.1 \\
\hline \multirow[t]{2}{*}{ Gender } & Male & 52.5 & 51.2 & 54.4 & -3.2 \\
\hline & Female & 47.5 & 48.8 & 45.6 & 3.2 \\
\hline \multirow[t]{3}{*}{ Supervisory status } & $\begin{array}{l}\text { Nonsupervisor/ } \\
\text { Team leader }\end{array}$ & 72.7 & 73.4 & 71.7 & 1.7 \\
\hline & Supervisor/manager & 25.4 & 24.9 & 26.1 & -1.2 \\
\hline & executive & 1.9 & 1.7 & 2.2 & -0.5 \\
\hline \multirow[t]{2}{*}{ Location } & Headquarters & 41.7 & 40.8 & 43.1 & -2.3 \\
\hline & Field & 58.3 & 59.2 & 56.9 & 2.3 \\
\hline
\end{tabular}


respond early than late. These findings seem to agree with the literature (Mayer and Pratt 1966; Gannon et al. 1971; Filion 1975), but this is not true of all demographics investigated. For example, Newman (1962) found respondents of higher socioeconomic status tended to respond earlier, while we find somewhat conflicting results. Those in Grades 13-15 within the General Schedule (GS) pay scale were more likely to be late responders than early responders. Furthermore, those within the GS 7-12 ranges were more likely to be early responders than late responders. (A higher grade with respect to the GS pay scale for U.S. federal government employees is associated with higher pay. For more information, see www.opm.gov/oca.) Two other differences worth mentioning are that employees with lower intentions to leave their current position are more likely to be late responders and that employees working at the agency's headquarters are more likely to be late responders as compared to employees working in a field office.

These demographic distributions were also examined for each agency. For brevity, none of those tables are given in this article, but several of the general findings noted above prevailed. For example, minority respondents were more likely to respond after the first two weeks in all 30 agencies. Those intending to leave were more likely to respond within two weeks in all but four agencies. The gender disparity was not found to be universal across agencies, however, as we found females were more likely to respond early in 17 out of 30 agencies. The other demographic comparisons were also mixed on an agency-byagency basis.

\section{Comparison of Early Responder and All-Responder Estimates}

The previous section compared the demographic characteristics of employees responding before or after the first two weeks of data collection. This section discusses the effects on the survey estimates by reducing the FEVS data collection period to two weeks. In particular, we compare the survey estimates that would be published if the FEVS data collection period were shortened to two weeks versus the estimates based on the full data collection period. We call the differences between these estimates the early-minus-all estimate differences. Positive differences signify that the early responders are more positive than all responders, while negative differences signify the opposite, that early responders were more negative than all responders. Subsection 4.1 expresses the earlyminus-all estimate difference in terms of the prevalence of late responders and the survey characteristics of employees responding before and after the first weeks of data collection. Subsections 4.2 and 4.3 use 2011 FEVS data to assess early-minus-all estimate differences at the governmentwide and agency levels, respectively. Subsections 4.4 and 4.5 further explore the agency-level results by examining relationships between early-minus-all estimate differences and agency-level characteristics and between early-minus-all differences and the levels of early-responder and all-responder estimates.

\subsection{Differences in Estimates Due to Reducing the Fielding Period}

Survey nonresponse can be modeled deterministically or stochastically. A deterministic model would assume that a population of individuals consists of $N_{\text {early }}$ individuals who always respond early, $N_{\text {late }}$ individuals who always respond late, and $N_{\text {never }}$ individuals who never respond. We will refer to estimates obtained when the survey is not reduced in 
length as all-responder estimates and to estimates obtained when the data collection period is reduced in length as early-responder estimates. Further assume that the estimates of interest are estimates of population means or proportions. Under a deterministic model for nonresponse, the early-minus-all estimate differences are estimates of

$$
E^{(i)}=\bar{X}_{\text {early }}^{(i)}-\bar{X}_{\text {all }}^{(i)},
$$

where

$\bar{X}_{\text {early }}^{(i)}=$ population mean for survey item $i$ for early responders, and

$\bar{X}_{\text {all }}^{(i)}=$ population mean for survey item $i$ for all responders.

Since

$$
\bar{X}_{\text {all }}^{(i)}=\frac{N_{\text {early }} \bar{X}_{\text {early }}^{(i)}+N_{\text {late }} \bar{X}_{\text {late }}^{(i)}}{N_{\text {early }}+N_{\text {late }}},
$$

where $\bar{X}_{\text {late }}^{(i)}$ is the population mean for survey item $i$ for all responders that are not early responders, it follows that

$$
E=\bar{X}_{\text {early }}^{(i)}-\frac{N_{\text {early }} \bar{X}_{\text {early }}^{(i)}+N_{\text {late }} \bar{X}_{\text {late }}^{(i)}}{N_{\text {early }}+N_{\text {late }}}=r_{\text {late }}\left(\bar{X}_{\text {early }}^{(i)}-\bar{X}_{\text {late }}^{(i)}\right),
$$

where

$$
r_{\text {late }}=\frac{N_{\text {late }}}{N_{\text {early }}+N_{\text {late }}}
$$

is the prevalence of late responders among all responders, that is, the expected proportion of all responders that are not early responders.

\subsection{Governmentwide Early-Minus-All Estimate Differences}

For all 30 agencies, the early-responder data were used to compute early-responder weights using the same procedures used in the 2011 FEVS all-respondent dataset. These weights were then used to calculate the percent positive estimates for the early responders. The early-minus-all estimate differences for the indices and sub-indices were computed by subtracting the index (or subindex) for all responders from the corresponding index (or subindex) for early responders. Both the early-responder weights and the all-responder weights contain adjustments for nonresponse calculated within nonresponse-adjustment cells defined by sampling-frame variables. This eliminates ignorable nonresponse biases (Little and Rubin 2002) associated with variables for which the missing-at-random assumption holds within the defined nonresponse-adjustment cells but it does not eliminate nonignorable nonresponse biases or additional ignorable nonresponse biases associated with variables not on the sampling frame. Hence, the early-minus-all estimate differences estimate not only the quantity defined in terms of population parameters by Equation (1) but also include differences in nonignorable nonresponse biases between early and late respondents.

Table 2 contains the governmentwide early-responder estimates, the all-responder estimates, and the early-minus-all estimate differences for the Employee Engagement and 


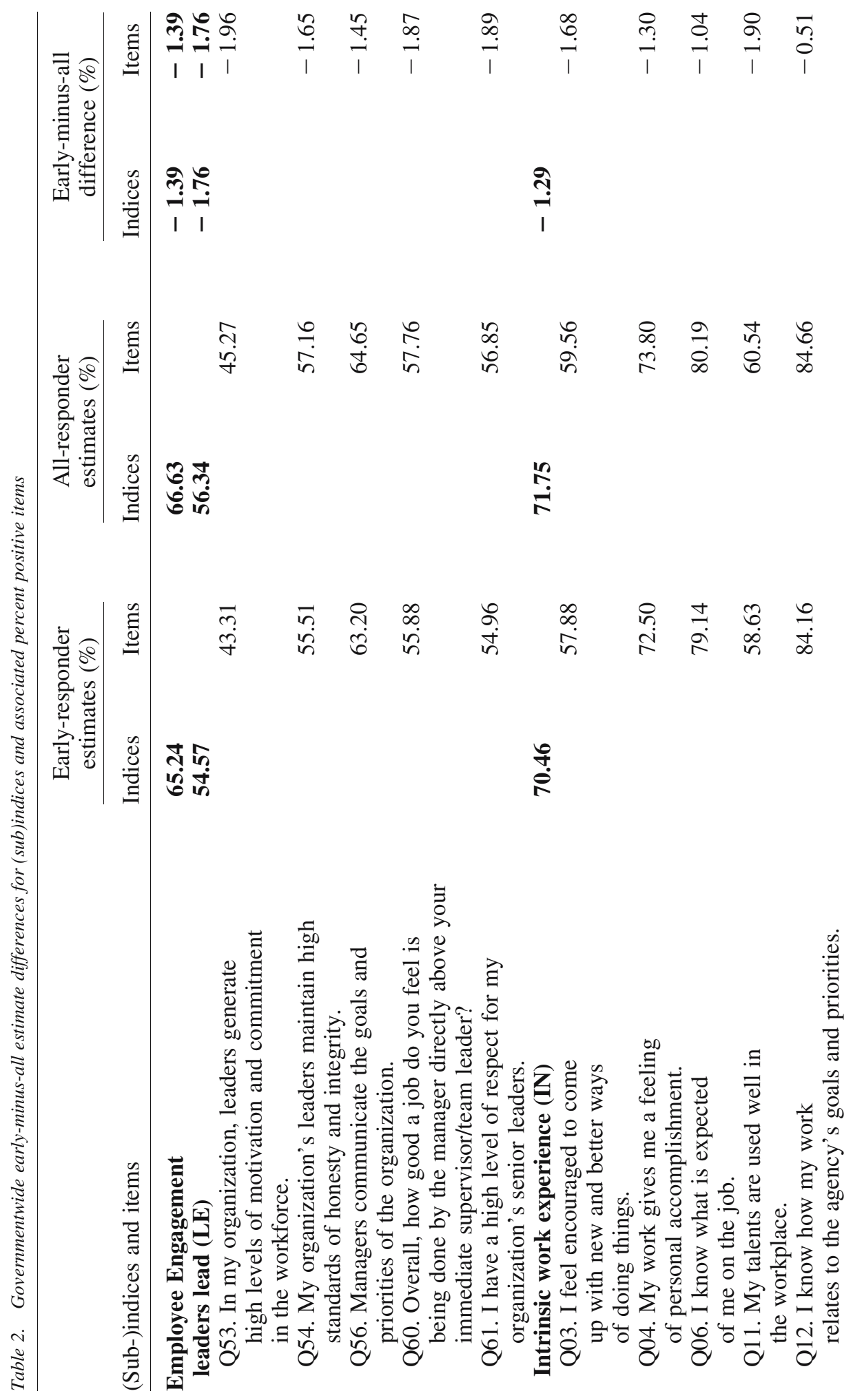




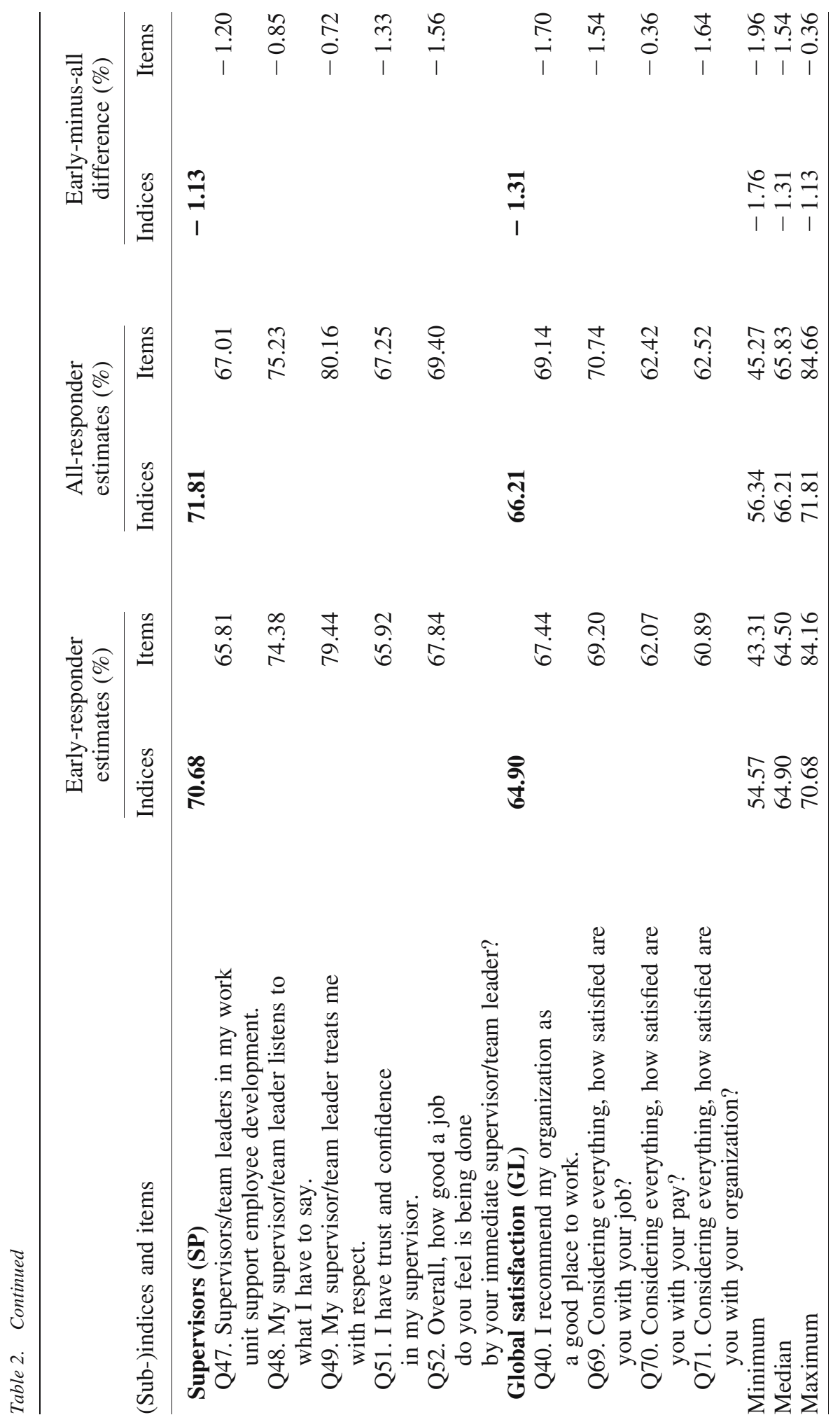


Global Satisfaction indices and the associated 19 items. All of the estimate differences were negative, ranging from -1.96 percent to -0.36 percent, indicating that overall the early responders were more negative than all responders. The median governmentwide early-minus-all estimate difference across the 19 items was -1.54 percent. All of the index differences were also negative, ranging from -1.76 percent to -1.13 percent.

Across the 19 items and five (sub)indices, smaller percent positive values were associated with more negative early-minus-all estimate differences. For the 19 items, the Pearson correlation between early-minus-all estimate difference and the early-responder estimates was 0.72 ; between early-minus-all estimate differences and all-responder estimates it was 0.70 . For the five (sub)indices, the Pearson correlation with early-minusall estimate differences was 0.96 for (sub)indices based on early-responder estimates and was 0.95 for those based on all-responder estimates. Because governmentwide earlyminus-all differences are negative, the positive correlation between early estimates and early-minus-all differences indicates that across items and (sub)indices, as percent positive values get larger the difference between early estimates and all-responder estimates moves closer to zero. In the next section we investigate these relationships across individual agencies.

\subsection{Agency-Level Early-Minus-All Estimate Differences}

Table 3a displays summary statistics for agency-level early-minus-all estimate differences for the five (sub)indices. The minimum and median-level early-minus-all estimate differences across agencies are negative, whereas the maximum early-minus-all estimate difference across agencies is positive. The median agency-level early-minusall estimate difference across agencies ranges from -2.00 percent (for Leaders Lead) to -1.12 (for Supervisors). The relationship between early-responder estimates and all-responder estimates found at the governmentwide level was also seen at the agency level; however, as shown in Table 3a, there are some agencies that did not exhibit this pattern, rather early responders were more positive than late responders for some agencies.

The 30 box plots in Figure 1 help to uncover why some early-minus-all differences are positive and why others are negative. The box plots show the distributions of early-minusall estimate differences across the two indices and three subindices for each agency. Though not shown, for each agency we also produced a box plot indicating the distribution of early-minus-all estimate differences across the 19 percent positive items. Within each agency, the range of the estimated early-minus-all difference for the indices and

Table 3a. Agency-level early-minus-all estimate differences for five (sub)indices

Agency-level early-minus-all difference (\%)

\begin{tabular}{lccccc} 
(Sub-)index & Minimum & Mean & Median & Maximum & Skewness \\
\hline Employee engagement & -3.93 & -1.39 & -1.39 & 0.19 & -0.47 \\
$\quad$ Leaders lead & -4.40 & -1.80 & -2.00 & 0.42 & 0.02 \\
Intrinsic work experiences & -3.92 & -1.21 & -1.13 & 0.40 & -0.80 \\
$\quad$ Supervisors & -3.49 & -1.16 & -1.12 & 1.10 & -0.30 \\
Global satisfaction & -5.92 & -1.49 & -1.28 & 0.30 & -1.52 \\
\hline
\end{tabular}




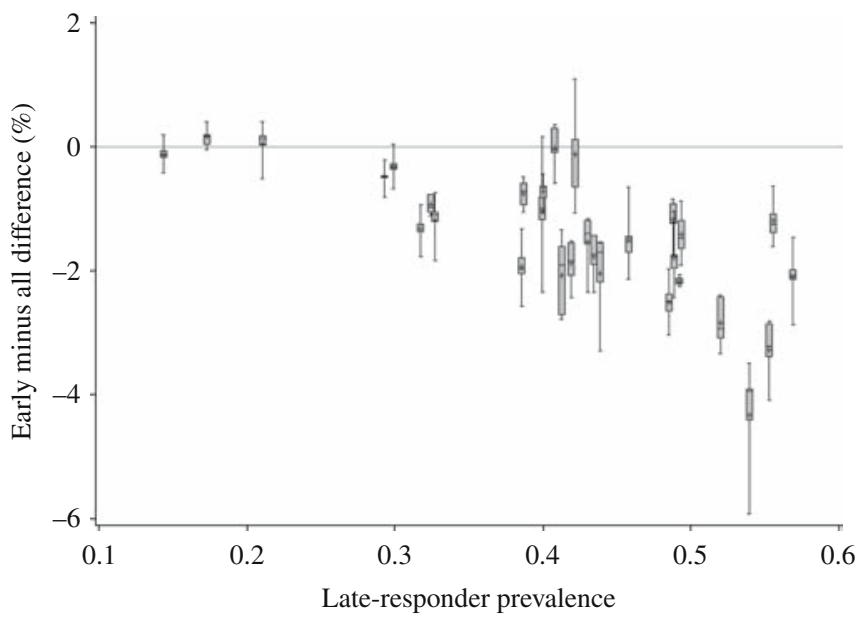

Fig. 1. "Skeletal" box plots by agency (in increasing order of agency's prevalence of late responders) indicating distributions of estimated early-minus-all estimate differences across percent positive indices. The end of the lower whisker is the minimum, and the end of the upper whisker is the maximum.

subindices was much smaller than the range of the early-minus-all estimate differences for the associated percent positive items. For both (sub)indices and percent positive items, when an agency has a higher prevalence of later responders, the early-minus-all estimate differences are more negative. In other words, as an agency's proportion of employees responding after two weeks increases, the percent positive estimates computed for that agency from all respondents are increasingly higher than the corresponding estimates computed from employees who responded in the first two weeks.

\subsection{Relationships between Agency-Level Early-Minus-All Estimate Differences and Agency-Level Characteristics}

This section investigates relationships between agency-level early-minus-all estimate differences and agency-level characteristics. Because of the tendency for agencies with a larger prevalence of late responders to have early-minus-all estimate differences that are more negative, we first investigated if an agency's prevalence of late responders could be predicted from its demographic characteristics. In particular, we developed an agencylevel linear regression model for predicting an agency's prevalence of late responders. An alternative modeling approach would have been to use logistic regression, in which the logistic transform of the prevalence of late responders is modeled. However, over the observed range of prevalence values -14.4 to 56.0 percent - the logistic transformation is accurately approximated by a linear relationship. The independent variables, calculated as unweighted means from the 2011 FEVS sampling frame data, described the following agency characteristics:

- Minority: Percentage of agency employees that are minorities,

- Gender: Percentage of agency employees that are male,

- Location: Percentage of agency employees assigned to the field, 
- Supervisory Status: Percentage of agency employees that are not supervisors or managers, and

- Federal Government Tenure: Agency average of employees' length of federal service in years.

We also had available each agency's average age of its employees, but it was highly correlated with length of federal service or tenure, so to avoid multicollinearity we did not include it as an independent variable. We estimated an agency's prevalence of late responders by using the all-responder weights to compute the weighted mean of a variable equal to 1.0 for late responders and equal to 0.0 for early responders. Table $3 b$ contains summary statistics for the agency characteristics.

Using the estimated prevalences of late responders and the associated independent variables for the 30 agencies, we calculated unweighted regression coefficients for an agency-level model containing an intercept and only linear terms involving the independent variables. Though the detailed results are not shown here, the $\mathrm{R}^{2}$ for the developed prediction model was 0.286 . The only regression coefficient that was statistically significant was the linear coefficient for the percentage of agency employees that are male $(p=0.013)$. If the agency prevalence of late responders is expressed as a percentage, this estimated regression coefficient equals 0.56. Since this regression coefficient was positive, agencies with a larger proportion of males had a larger proportion of their employees who reported later or after two weeks from the start of data collection. In particular, if two agencies differ by ten percentage points in their proportion of males, then the agency with the larger proportion of males is predicted to have a prevalence of late responders that is 5.6 percentage points greater than the agency with a smaller proportion of males.

Next, we developed a set of models that predicted the agency-level early-minus-all estimate differences for the (sub)indices from the agency-level characteristics listed in Table 3b. Equation 1 suggested that if the early-minus-all estimate difference was the dependent variable, then the independent variables should all include $r_{\text {late }}$, an agency's prevalence of late responders. Alternatively, in order to reduce heteroscedasticity one can transform the prediction models by dividing both sides by a power of $r_{\text {late }}$. Following the suggestion of Carrol and Ruppert (1988, 34), we assessed the need for such

Table 3b. Summary statistics for agency characteristics $(n=30)$

\begin{tabular}{|c|c|c|c|c|c|}
\hline Characteristic & Minimum & Mean & Median & Maximum & Skewness \\
\hline $\begin{array}{l}\text { Late-responder } \\
\text { prevalence }(\%)\end{array}$ & $14.4 \%$ & $40.9 \%$ & $42.1 \%$ & $56.0 \%$ & -0.78 \\
\hline Male prevalence $(\%)$ & $32.2 \%$ & $53.4 \%$ & $55.4 \%$ & $73.4 \%$ & -0.15 \\
\hline Minority prevalence $(\%)$ & $20.3 \%$ & $36.9 \%$ & $32.8 \%$ & $77.0 \%$ & 1.34 \\
\hline $\begin{array}{l}\text { Proportion located in } \\
\text { the field }(\%)\end{array}$ & $11.6 \%$ & $69.0 \%$ & $74.2 \%$ & $97.4 \%$ & -0.97 \\
\hline $\begin{array}{l}\text { Proportion } \\
\quad \text { nonsupervisors }(\%)\end{array}$ & $76.8 \%$ & $85.8 \%$ & $85.7 \%$ & $91.0 \%$ & -0.57 \\
\hline $\begin{array}{l}\text { Average length of service } \\
\text { (years) }\end{array}$ & 10.7 & 16.4 & 16.7 & 20.3 & -0.54 \\
\hline
\end{tabular}


transformations by computing the Spearman rank correlation between the squared residuals and the predicted values produced by each model. The Spearman correlations for the untransformed models were between -0.04 and 0.09 . We concluded that transformations were not needed. For example, when both sides were divided by $r_{\text {late }}$ the Spearman correlations were between 0.02 and 0.30 .

The independent variables for the untransformed models are listed in the first column of Table 4. Though Equation 1 suggested each of these models should not contain an intercept, we initially included an intercept in order to calculate the associated $\mathrm{R}^{2}$ values. The first row of Table 4 contains the unadjusted $\mathrm{R}^{2}$ values, ranging from 0.74 to 0.78 , and the associated root-mean-square errors for prediction for each model when an intercept is included. In each model, the intercept was not significantly different from zero. We then re-estimated the regression coefficients for models not containing intercepts. Columns 2 through 5 of Table 4 contain the estimated coefficients, and those that are significantly different from zero $(p \leq 0.05)$ are highlighted.

The coefficients for $\left(r_{\text {late }}\right)^{2}$ were statistically significant in all five models and coefficients for $r_{\text {late }}$ were statistically significant in three of the five models. All other coefficients were not significant, except that the interactions of the minority percentage with $r_{\text {late }}$ or $\left(r_{\text {late }}\right)^{2}$ were significant in models for the Employee Engagement Index and one of its subindices (Intrinsic Work Experience) and for the Global Satisfaction index. In addition, the interaction of the average length of federal service with $r_{\text {late }}$ was significantly different from zero only in the model for the Supervisors subindex. These models show that across the (sub)indices, the agency prevalence of late responders and also the square of this prevalence, along with interactions with the prevalence of minorities and length of service with the agency, were significant predictors of the difference in early-minus-all estimates. Based on these findings of significant predictors, we performed additional analyses to investigate the behavior of the developed models.

Table 5 examines predicted early-minus-all estimate differences for an "average" agency (i.e., $d()=0$ in the Table 4 coefficient expressions) and the effect of an increase in minority prevalence for the three indices or subindices in which the agency-percentage-ofminorities coefficients were statistically significant. These three models predict the earlyminus-all differences for Intrinsic Work Experience, Employee Engagement, and Global Satisfaction. The Supervisors subindex was modeled separately as it had different predictors. The different rows of Table 5 correspond to different levels of the prevalence of late responders. The rows at the top of Table 5 have a low prevalence of late responders that is, nearly all of the agency's responding employees respond during the first two weeks of data collection. The rows at the bottom of Table 5 have a high prevalence of late responders - that is, a large proportion of the agency's responding employees respond after the first two weeks of data collection.

Columns 2 through 4 of Table 5 contain the results of using the models to predict the early-minus-all estimate difference for different values of the prevalence of late responders for an "average" agency - that is, for an agency in which all of its demographic characteristics are equal to the unweighted all-agency average of the demographic characteristics. For a particular value of an agency's prevalence of late responders, the predicted values of early-minus-late estimate differences are very close to each other across the four indices and subindices. 


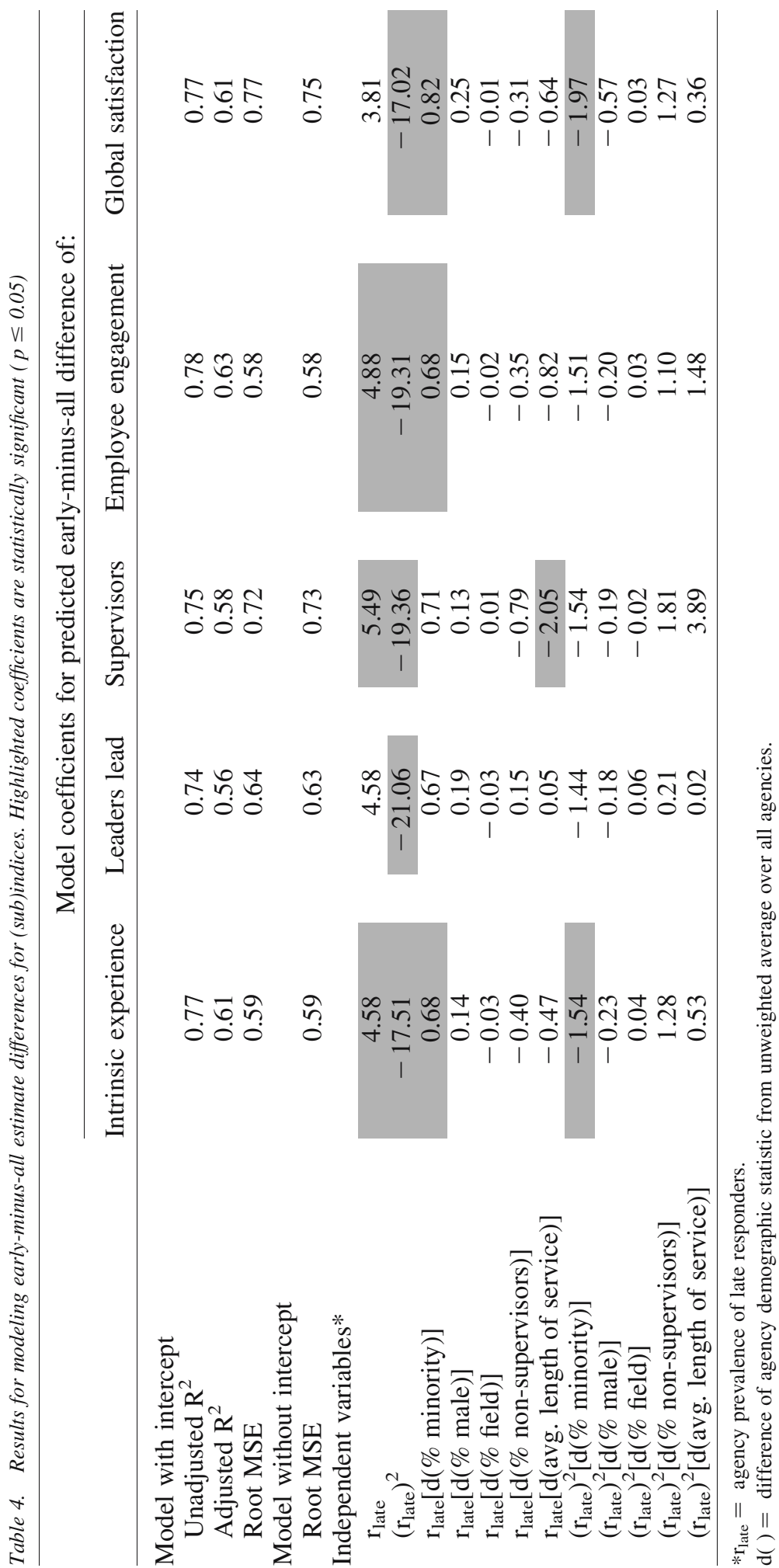


Table 5. Model predictions for agency-level early-minus-all estimate differences for Intrinsic Work Experience $(I N)$, Employee Engagement (EE), and Global Satisfaction (GL) (sub)indices

\begin{tabular}{|c|c|c|c|c|c|c|}
\hline \multirow[b]{2}{*}{ Prevalence of late responders } & \multicolumn{3}{|c|}{$\begin{array}{l}\text { Predicted early-minus-all } \\
\text { estimate difference for } \\
\text { "average" agency }(\%) \text { : }\end{array}$} & \multicolumn{3}{|c|}{$\begin{array}{c}\text { Predicted additive effect } \\
\text { of increase in minority } \\
\text { prevalence* }\end{array}$} \\
\hline & IN & $\mathrm{EE}$ & GL & IN & $\mathrm{EE}$ & GL \\
\hline 0.10 & 0.3 & 0.3 & 0.2 & 0.3 & 0.3 & 0.3 \\
\hline 0.20 & 0.2 & 0.2 & 0.1 & 0.4 & 0.4 & 0.4 \\
\hline 0.30 & -0.2 & -0.3 & -0.4 & 0.3 & 0.3 & 0.3 \\
\hline 0.40 & -1.0 & -1.1 & -1.2 & 0.1 & 0.2 & 0.1 \\
\hline 0.50 & -2.1 & -2.4 & -2.4 & -0.2 & -0.2 & -0.4 \\
\hline 0.60 & -3.6 & -4.0 & -3.8 & -0.7 & -0.7 & -1.1 \\
\hline
\end{tabular}

*Predicted effect on early-minus-all estimate difference of a +5 percentage points difference in agency minority percentage from average minority percentage $(\%)$

The predicted early-minus-all estimate differences for an "average" agency decrease to zero and then become more negative as the proportion of late responders increases. In particular, note that when an agency's prevalence of late responders is less than 30 percent, the predicted early-minus-late differences for an "average" agency are positive. This indicates that in such agencies the early responders have higher average scores for the modeled indices and subindices than do all responders. On the other hand, when an agency's prevalence of late responders is 30 percent or greater the entries in columns 2 through 4 for an "average" agency are negative. This indicates that in these agencies the early responders have lower average scores for the modeled indices and subindices. These two results suggests that at some point in time in an "average" agency's data collection period there may be a peak in the average value of the modeled indices and subindices among employees responding at this point in time. For agencies with a low prevalence of late responders, two weeks into the data collection period occurs after the peak, so the average of the early responders exceeds the average of the late responders, and hence the

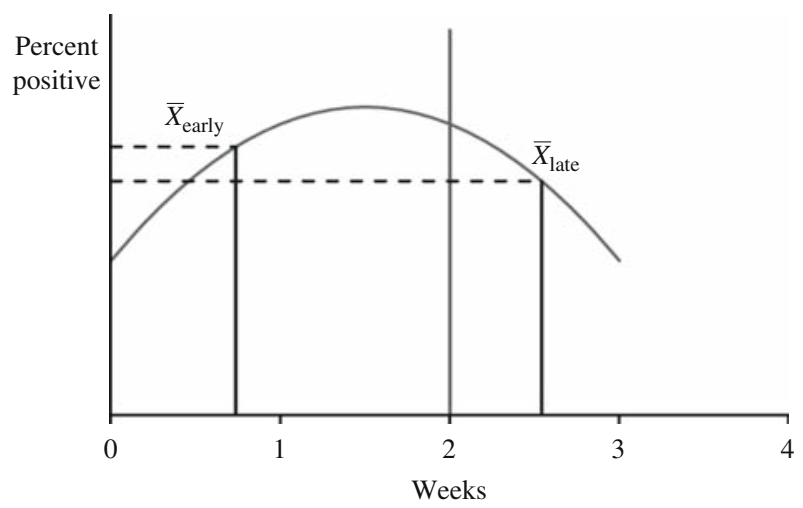

Fig. 2a. Possible explanation for a positive early-minus-all estimate difference. Because prevalence of late responders is low, the peak of percent positive for responses by time occurs less than two weeks into the data collection period. The overall percent positive for responses for early responders is greater than the overall percent positive responses for late responders, which produces a positive early-minus-all estimate difference. 
early-minus-all estimate difference is positive (see Figure 2a). On the other hand, for agencies with a high prevalence of late responders, two weeks into the data collection period occurs before the peak, so the average of the early responders is less than the average of the late responders, and hence the early-minus-all estimate difference is negative (see Figure $2 \mathrm{~b}$ ).

Columns 5 through 7 of Table 5 predict the additive effect on early-minus-all estimate differences resulting from an agency's minority percentage differing by +5 percentage points from the unweighted all-agency average minority percentage. These results predict the difference in early-minus-all estimate differences between a particular agency and an "average" agency, where the particular agency's minority percentage differs by +5 percentage points from the minority percentage for the "average" agency. These results predict that the particular agency's early-minus-all estimate differences will be more positive for a low prevalence of late responders and will be more negative for a high prevalence of late responders. In particular, for agency prevalences of late responders less than 50 percent, the predicted early-minus-all differences in columns 5 through 7 are positive. This indicates that among those agencies in which 50 percent or fewer of the agency's responding employees responded in the first two weeks, the agencies with a higher proportion of minorities compared to the "average" agency will have more positive early-minus-all differences in the modeled indices and subindices than the "average" agency. For agency prevalences of late responders of 50 percent or greater, however, the predicted early-minus-all estimate differences in columns 5 through 7 of Table 5 are negative. This indicates that among agencies in which 50 percent or fewer of the agency's responding employees responded in the first two weeks, the agencies with higher proportions of minorities compared to the "average" agency will have more negative early-minus-all estimate differences in the modeled indices and subindices.

Table 6 examines the predicted early-minus-all estimate differences for an "average" agency and the additive effect of an increase in agency-average length of service for the Supervisors subindex model. Column 2 of Table 6 contains the predictions for different prevalences of late responders for an "average" agency - that is, an agency in which all of its demographic characteristics are equal to the unweighted all-agency average of the

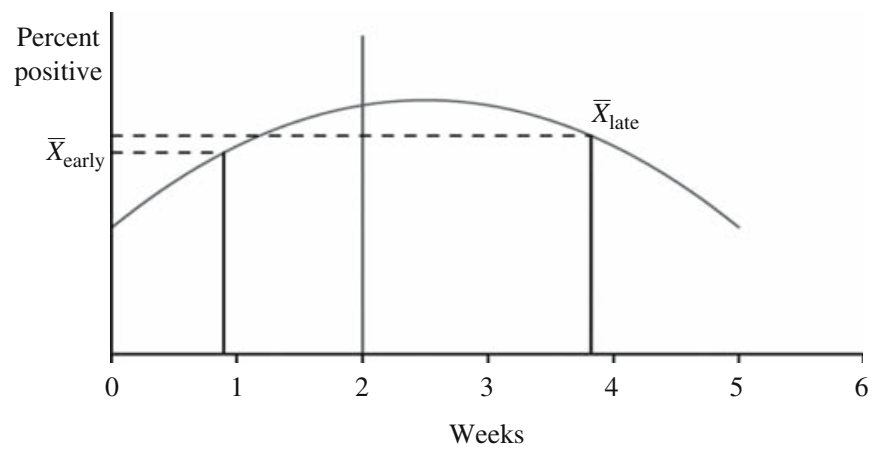

Fig. 2b. Possible explanation for a negative early-minus-all estimate effect. Because the prevalence of late responders is high, the peak of percent positive for responses by time occurs more than two weeks into the data collection period. The overall percent positive for responses for early responders is less than the overall percent positive for responses for late responders, which produces a negative early-minus-all estimate difference. 
Table 6. Model predictions for agency-level early-minus-all estimate differences for supervisors subindex

\begin{tabular}{lcc}
\hline $\begin{array}{l}\text { Prevalence of } \\
\text { late responders }\end{array}$ & $\begin{array}{c}\text { Predicted early-minus-all } \\
\text { estimate difference for } \\
\text { "average" agency }(\%):\end{array}$ & $\begin{array}{c}\text { Predicted additive } \\
\text { effect of increase in } \\
\text { agency average federal } \\
\text { length of service* }\end{array}$ \\
\hline 0.10 & 0.4 & -0.8 \\
0.20 & 0.3 & -1.3 \\
0.30 & -0.1 & -1.3 \\
0.40 & -0.9 & -1.0 \\
0.50 & -2.1 & -0.3 \\
0.60 & -3.7 & 0.9 \\
\hline
\end{tabular}

$*$ Effect of +5 years difference in agency average federal length of service (LOS) from average LOS averaged over all agencies $(\%)$

demographic characteristics. For a particular value of an agency's prevalence of late responders, the predicted values of the early-minus-all estimate differences in Column 2 of both Table 5 and Table 6 are very close to each other, with the predicted values becoming more negative as the prevalence of late responders increases. Column 3 of Table 6 contains the predicted effects on early-minus-all estimate differences resulting from an agency's average of employees' length of federal service differing by +5 years from the unweighted all-agency average of employee's length of federal service. Note that the sum of columns 2 and 3 is negative. This suggests that for agencies in which the average length of federal service differs by at least +5 years from that for the "average" agency, the point in time of the peak value of the Supervisors subindex for responding employees occurs after the first two weeks of data collection, or maybe there is no peak, with the average percent positive of responding employees increasing with time.

\subsection{Relationships between Agency-Level Early-Minus-All Estimate Differences and Levels of Early-Responder and All-Responder Estimates}

In Subsection 4.2, we observed that smaller percent positive values for the governmentwide indices and subindices for both early responders and all responders were associated with more negative early-minus-all estimate differences. To determine if this also held at the agency level, we developed an agency-level model for each (sub)index to predict early-minus-all estimate differences from early-responder estimates as well as a model to predict early-minus-all estimate differences from all-responder estimates. The right-hand side of these models contained an intercept and either the early-responder estimate or the all-responder estimate multiplied by a slope coefficient:

$$
E^{(i)}=\text { intercept }_{\text {early }}^{(i)}+\text { slope }_{\text {early }}^{(i)} \bar{X}_{\text {early }}^{(i)}+\text { error }_{\text {early }}^{(i)}
$$

and

$$
E^{(i)}=\text { intercept }_{\text {late }}^{(i)}+\text { slope }_{\text {late }}^{(i)} \bar{X}_{\text {late }}^{(i)}+\text { error }_{\text {late }}^{(i)}
$$


Table 7. Slope coefficients and $R^{2}$ values for predicting early-minus-all differences

\begin{tabular}{|c|c|c|c|c|c|}
\hline \multirow[b]{2}{*}{ (Sub-)Index } & \multicolumn{2}{|c|}{ Slope coefficients } & \multicolumn{3}{|c|}{ Adjusted $\mathrm{R}^{2}$ values } \\
\hline & $\begin{array}{l}\text { Early- } \\
\text { responder } \\
\text { estimate }\end{array}$ & $\begin{array}{l}\text { All- } \\
\text { responder } \\
\text { estimate }\end{array}$ & $\begin{array}{c}\text { Agency } \\
\text { charact- } \\
\text { eristics }\end{array}$ & $\begin{array}{l}\text { Early- } \\
\text { responder } \\
\text { estimate }\end{array}$ & $\begin{array}{c}\text { All- } \\
\text { responder } \\
\text { estimate }\end{array}$ \\
\hline Employee engagement & 0.13 & 0.12 & 0.63 & 0.42 & 0.26 \\
\hline Leaders lead & 0.11 & 0.10 & 0.56 & 0.42 & 0.28 \\
\hline $\begin{array}{r}\text { Intrinsic work } \\
\text { experiences }\end{array}$ & 0.14 & 0.11 & 0.61 & 0.33 & 0.14 \\
\hline Supervisors & 0.12 & 0.09 & 0.58 & 0.26 & 0.09 \\
\hline Global satisfaction & 0.11 & 0.09 & 0.61 & 0.29 & 0.13 \\
\hline
\end{tabular}

The intercepts and slope coefficients were statistically significant $(p \leq 0.05)$ in all of the models for predicting early-minus-all estimate differences from early-responder or all-responder estimates.

Table 7 contains the values of the estimated slope coefficients and compares the $\mathrm{R}^{2}$ values to those for the models discussed in the preceding section in which early-minus-all differences were predicted from agency characteristics. The estimated slope coefficients for predicting early-minus-all estimate differences from early-responder estimates are between 0.11 and 0.14 , with the largest being for Intrinsic Work Experience. Hence, on average if two agencies' early-responder estimates for Intrinsic Work Experience differ by five percentage points, then their corresponding all-responder estimates will differ by $5 *(1+0.14)=7$ percentage points.

The estimated slope coefficients for predicting early-minus-all estimate differences from the all-responder estimates are slightly smaller, ranging between 0.09 and 0.12, with largest being for Employee Engagement. Hence, on average, if two agencies' all-responder estimates for Employee Engagement differ by eight percentage points, then their corresponding early-responder estimate will differ by $8 *(1-0.12)=7$ percentage points. Tables 4,5 , and 6 indicate that the variation across agencies in early-minus-all differences can be explained by variation in agency characteristics. Table 7, on the other hand, indicates that variation across agency in early-minus-all differences can be explained by the variation in agency-level estimates calculated from early responders or, alternatively, in the estimates calculated from all responders.

\section{Conclusions}

This article explored the impact of shortening the fielding period of the FEVS using the results from a subset of 30 agencies participating in the 2011 FEVS. If the FEVS data collection period were to be shortened to two weeks and no other changes were made to the timing of FEVS survey administration activities, the analyses conducted suggest that the response rate, the demographic profile of respondents, and the survey estimates for the Employee Engagement and Global Satisfaction indices could change significantly. 
By shortening the survey fielding period, fewer employees would have the chance to respond. The number of completed surveys for the 2011 FEVS would have been reduced by approximately 41 percentage points (ranging from 14 percent to 57 percent across agencies). However, it is unclear whether a reduction of this magnitude would be observed in practice in future FEVS administrations. One potential reason is that sampled employees receive a barrage of tailored notifications indicating the fielding period is about to end, which generally results in a surge of completed surveys. This study artificially shortened the fielding period without attempting to account for the effect of a pending deadline. Further research could explore ways to model and incorporate this effect into the process of estimating early-minus-all percent positive differences.

The demographic profiles of those who responded in the first two weeks (early responders) were significantly different from late responders. Early responders were more likely to be nonminority employees, female employees, older employees, or employees who intend to leave their current position for another job either within or outside the government. The late responders were more likely to be higher-grade employees, supervisors, executives, male employees, and younger employees.

In addition to demographic profile differences, shortening the fielding period results in a decrease of governmentwide percent positive estimates and associated indices, with changes in percent positive estimates ranging between -1.76 percent and -1.13 percent depending on the index. However, the relationship is not straightforward and uniform. These differences are influenced by the apportionment of early/late responders and the prevalence of longer tenured and/or nonminority employees. If an agency has a higher proportion of early responders, it tends to have higher percent positive estimates, on average. As the share of late responders increases, the percent positive estimates tend to be lower, as calculated from only the early responders. This translates to the indices, which are simple averages of the percent positive estimates. For example, with the Global Satisfaction and Employee Engagement indices as well as the Intrinsic Work Experience subindex, there was an additive impact associated with the proportion of minority employees in the agency. If an agency has a lower proportion of late responders and a higher proportion of minorities, the early responders will tend to yield higher average percent positive estimates and (sub)index scores. For the Supervisors subindex, an opposite relationship was found for length of service in the federal government. Almost regardless of the proportion of late responders, if an agency has an average length of federal services +5 years from the average agency, the early responders will tend to have lower average percent positive estimates on the indices. Lastly, further analysis showed that an item's percent positive estimate itself seems to impact the magnitude of the earlyminus-all difference. Specifically, the smaller the percent positive estimate, the more negative the difference.

Despite many of the factors discussed above falling outside the survey sponsor's locus of control, one general best practice recommendation appears to emerge from scrutinizing the data in Appendix A. Although not explicitly stated elsewhere in the article, there is clearly a positive association between an agency's prevalence of early responders and its overall response rate. Therefore, it seems plausible that efforts to boost the overall response rate could, in turn, boost the portion of employees who respond promptly, thereby tempering some of the noted item score differentials and reintroducing the 
possibility of a shortened fielding period. From our own practical experience conducting employee surveys, we find that the agencies consistently generating higher response rates are those in which senior officials aggressively publicize the survey via internal agency correspondence and other pertinent media outlets to reach as many employees as possible in the weeks immediately preceding the survey launch. Because many of these surveys are recurring, as is the case with the FEVS, another critical element is to communicate specific actions taken as a result of a prior survey administration. This helps foster a sense of employee empowerment in taking the survey, a belief that the feedback provided will be used to drive organizational change. An item can be included on the survey instrument to help gauge the organization's success in this regard. For example, an item was added to the FEVS instrument in 2010, asking employees about their agreement with the statement "I believe the results of this survey will be used to make my agency a better place to work."

In conclusion, this article presents evidence, based on the 2011 FEVS survey administration, that reducing the field period to two weeks would have ramifications for the response rates, the demographic profile for those responding during that time frame, and the attitudinal measures and aggregates thereof estimated by the survey. Although it was the first known comparison of early versus late responders in a self-administered employee survey of our population of interest, U.S. government employees, it follows a long tradition of similar analyses in the survey methodology literature. In addition, there is a wide body of survey literature on the causes and correlates of the decision to respond to a survey (Groves and Couper 1998), attempts to tailor contact attempts to maximize response (Kreuter 2013; Weeks 1987; Wagner 2013), as well as sociological (Dillman et al. 2009) and psychological (Groves et al. 2000) factors associated with survey participation. We feel that studies such as ours would benefit greatly if this literature were expanded to not only explain the dichotomy of whether one ultimately ignores or answers the call to participate in a survey, but the point during the fielding period when one makes his or her final decision. 


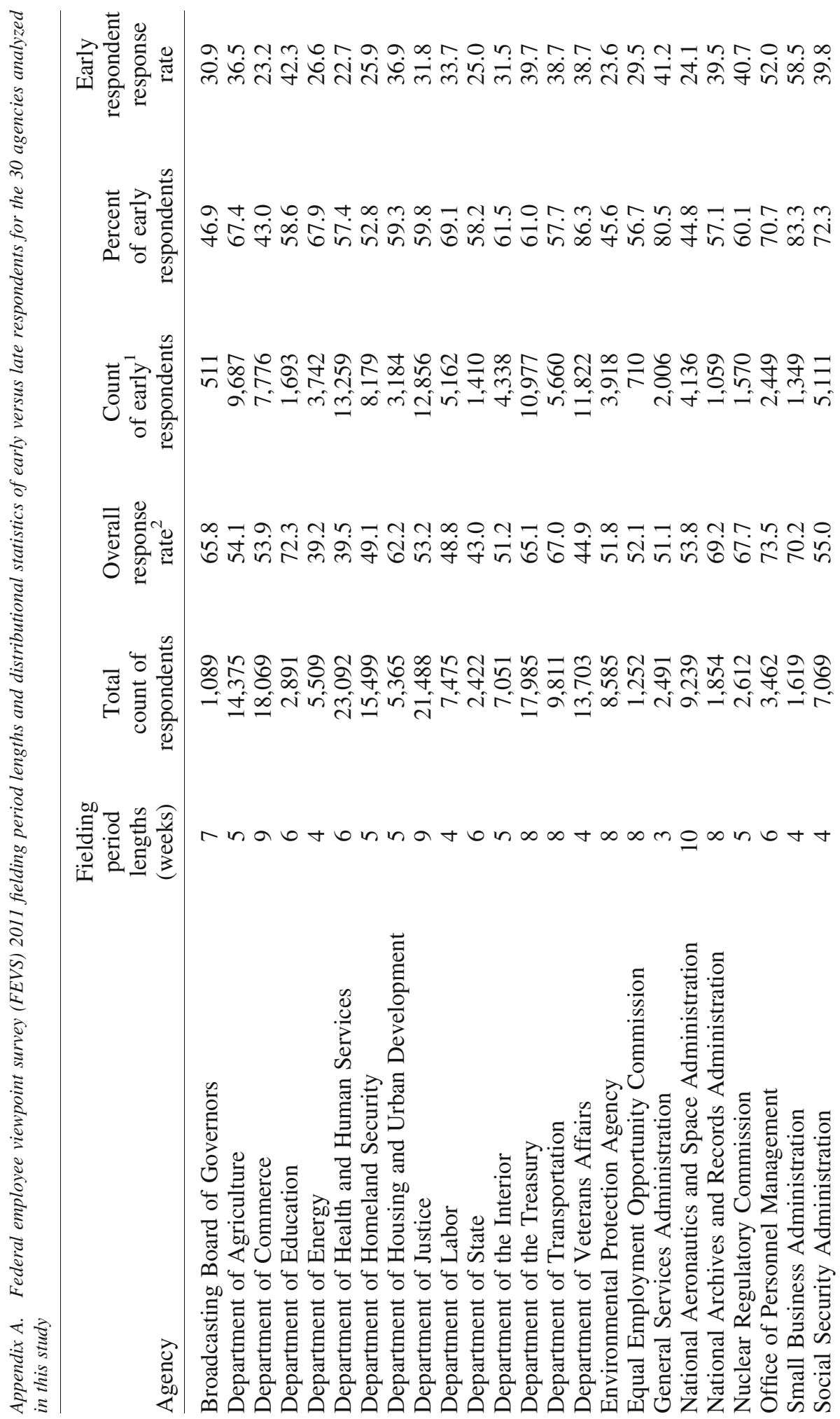




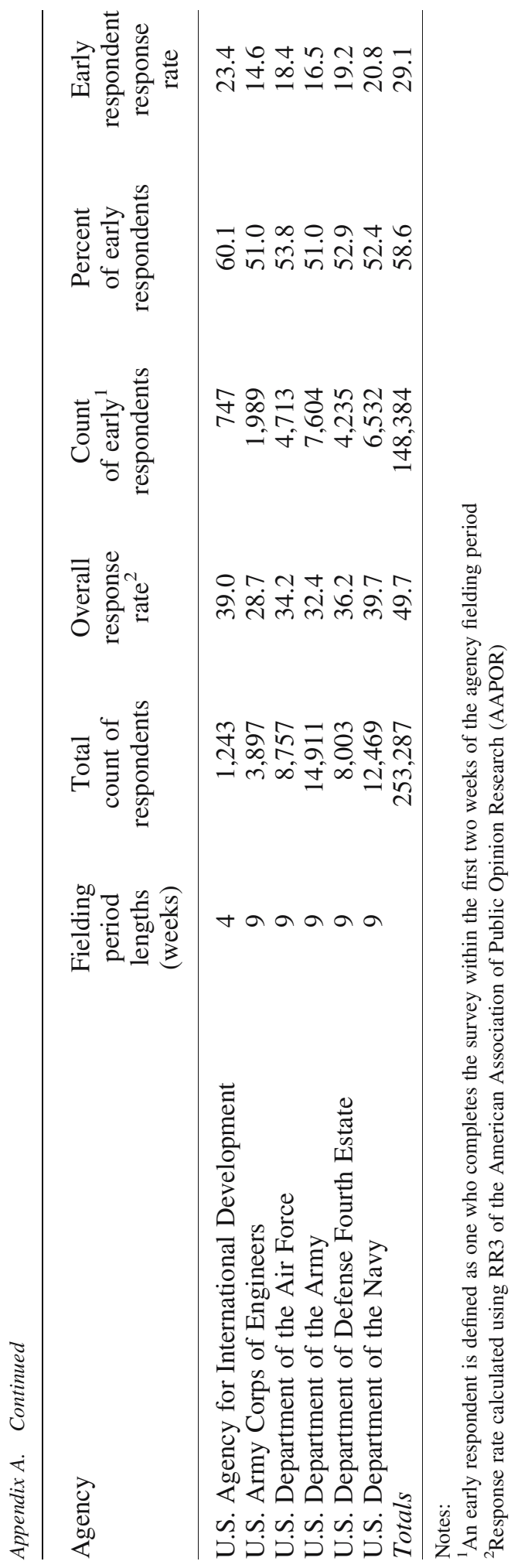




\section{References}

American Association for Public Opinion Research. 2009. Standard Definitions: Final Dispositions of Case Codes and Outcome Rates for Surveys. Sixth Edition. Available at: http://www.aapor.org/Content/NavigationMenu/ResourcesforResearchers/ StandardDefinitions/StandardDefinitions2009new.pdf (accessed January 27, 2014).

Baruch, Y. and B.C. Holtom. 2008. "Survey Response Rate Levels and Trends in Organizational Research.” Human Relations 61: 1139-1160. DOI: http://dx.doi.org/10. 1177/0018726708094863.

Bates, N. and K. Creighton. 2000. "The Last Five Percent: What Can We Learn from Difficult/Late Interviews?" In Proceedings of the Section on Government Statistics: American Statistical Association, August 13, 2000. 120-125. Alexandria, VA: American Statistical Association.

Baur, E.J. 1947. "Response Bias in a Mail Survey." Public Opinion Quarterly 11: 595-600. DOI: http:/dx.doi.org/10.1086/265895.

Borg, I. and T. Tuten. 2003. "Early versus Later Respondents in Intranet-Based, Organizational Surveys.” Journal of Behavioral and Applied Management 4: 134-145.

Carroll, R.J. and D. Ruppert. 1988. Transformation and Weighting in Regression. New York, NY: Chapman and Hall.

Dillman, D.A., J.D. Smyth, and L.M. Christian. 2009. Internet, Mail, and Mixed-Mode Surveys: The Tailored Design Method, $3^{\text {rd }}$ ed. Hoboken, NJ: Wiley.

Filion, F. 1975. "Estimating Bias Due to Nonresponse in a Mail Survey." Public Opinion Quarterly 39: 482-492. DOI: http://dx.doi.org/10.1086/268245.

Gannon, M.J., J.C. Nothern, and S.J. Carroll. 1971. "Characteristics of Nonrespondents Among Workers.” Journal of Applied Psychology 55: 586-588. DOI: http://dx.doi.org/ 10.1037/h0031907.

Green, K.E. 1991. "Reluctant Respondents: Differences Between Early, Late, and Nonresponders to a Mail Survey." The Journal of Experimental Education 59: 268-276. DOI: http://dx.doi.org/10.1080/00220973.1991.10806566.

Groves, R.M. and M. Couper. 1998. Nonresponse in Household Interview Surveys. New York, NY: Wiley. DOI: http://dx.doi.org/10.1002/9781118490082.index.

Groves, R.M., E. Singer, and A. Corning. 2000. "Leverage-Saliency Theory of Survey Participation: Description and an Illustration.” Public Opinion Quarterly 64: 299-308. DOI: http://dx.doi.org/10.1086/317990.

De Leeuw, E. and W. de Heer. 2002. "Trends in Household Survey Nonresponse: a Longitudinal and International Comparison.” In Survey Nonresponse, edited by Robert M. Groves, et al. New York, NY: Wiley. DOI: http://dx.doi.org/10.1093/poq/nfl033.

Ellis, R.A., C.M. Endo, and J.M. Armer. 1970. "The Use of Potential Nonrespondents for Studying Nonresponse Bias.” Pacific Sociological Review 13: 103-109. DOI: http://dx. doi.org/10.2307/1388313.

Erickson, T.J. 2005. "The 21 ${ }^{\text {st }}$ Century Workplace: Preparing for Tomorrow's Employment Trends Today." (Testimony submitted before the U.S. Senate Committee on Health, Education, Labor, and Pensions, May 26, 2005). Available at: http://www. help.senate.gov/hearings/index.cfm?year $=2005 \&$ month $=05$ (accessed December 2012). 
Jacoby, J. and M.S. Matell. 1971. "Three-Point Likert Scales are Good Enough.” Journal of Marketing Research 8: 495-500. DOI: http://dx.doi.org/10.2307/3150242.

Kalton, G.F. and I. Flores-Cervantes. 2003. "Weighting Methods." Journal of Official Statistics 19: 81-97.

Kraut, A.I. 1996. Organizational Surveys: Tools for Assessment and Change. San Francisco, CA: Jossey-Bass.

Kreuter, F. 2013. Improving Surveys with Paradata: Analytic Uses of Process Information. Hoboken, NJ: Wiley. DOI: http://dx.doi.org/10.1002/9781118596869.ch1.

Little, R.J.A. and D.B. Rubin. 2002. Statistical Analysis with Missing Data. Second ed. New York, NY: Wiley. DOI: http://dx.doi.org/10.1002/sim.1697.

Macey, W.H. and B. Schneider. 2008. "The Meaning of Employee Engagement." Industrial and Organizational Psychology 1: 3-30. DOI: http://dx.doi.org/10.1111/j. 1754-9434.2007.0002.x.

Mayer, C.S. and R.W. Pratt., Jr. 1966. “A Note on Nonresponse in a Mail Survey.” Public Opinion Quarterly 30: 637-646. DOI: http://dx.doi.org/10.1086/267461.

Newman, S.W. 1962. "Differences between Early and Late Respondents to a Mailed Survey." Advertising Research 2: 37-39.

Pace, R.C. 1939. "Factors Influencing Questionnaire Returns from Former University Students." Journal of Applied Psychology 23: 388-397. DOI: http://dx.doi.org/10. 1037/h0063286.

Rogelberg, S.G. and J.M. Stanton. 2007. "Understanding and Dealing with Organizational Survey Nonresponse.” Organizational Research Methods 10: 195-209. DOI: http://dx. doi.org/10.1177/1094428106294693.

Schwirian, K.P. and H.R. Blaine. 1966. "Questionnaire-Return Bias in the Study of BlueCollar Workers.” Public Opinion Quarterly 30: 656-663. DOI: http://dx.doi.org/10. $1086 / 267463$.

Sonquist, J.A., E.L. Baker, and J.N. Morgan. 1974. Searching for Structure. Ann Arbor, MI: Institute for Social Research, University of Michigan.

U.S. Office of Personnel Management. 2011. 2011 Federal Employee Viewpoint Survey: Governmentwide Management Report. Washington, DC: OPM. Available at: http:// www.fedview.opm.gov/2011/Published (accessed January 27, 2014).

Wagner, J. 2013. "Adaptive Contact Strategies in Telephone and Face-to-Face Surveys." Survey Research Methods 7: 45-55. DOI: http://dx.doi.org/10.1002/9781118596869.ch7. Weeks, M.F. 1987. "Optimal Call Scheduling for a Telephone Survey." Public Opinion Quarterly 51: 540-549. DOI: http://dx.doi.org/10.1086/269056.

Received December 2012

Revised September 2014

Accepted September 2014 